\title{
BMI open Pulmonary metastasectomy for sarcoma: a systematic review of reported outcomes in the context of Thames Cancer Registry data
}

\author{
Tom Treasure, ${ }^{1}$ Francesca Fiorentino, ${ }^{2}$ Marco Scarci, ${ }^{3}$ Henrik Møller, ${ }^{4}$ Martin Utley ${ }^{1}$
}

To cite: Treasure T,

Fiorentino $\mathrm{F}$, Scarci M, et al. Pulmonary metastasectomy for sarcoma: a systematic review of reported outcomes in the context of Thames Cancer Registry data. BMJ Open 2012;2:e001736. doi:10.1136/bmjopen-2012001736

- Prepublication history and additional material for this paper are available online. To view these files please visit the journal online (http://dx.doi.org/10.1136/ bmjopen-2012-001736).

Received 6 July 2012 Accepted 15 August 2012

This final article is available for use under the terms of the Creative Commons Attribution Non-Commercial 2.0 Licence; see http://bmjopen.bmj.com

${ }^{1}$ Clinical Operational Research Unit, Department of Mathematics, UCL (), London, UK

${ }^{2}$ National Heart and Lung Institute, Cardiothoracic Surgery, Imperial College London, London, UK ${ }^{3}$ Department of Thoracic Surgery, Papworth Hospital NHS Foundation Trust, Cambridge, UK

${ }^{4}$ Thames Cancer Registry, King's College London, London, UK

\section{Correspondence to} Dr Tom Treasure; tom.treasure@gmail.com

\section{ABSTRACT}

Objectives: Sarcoma has a predilection to metastasis to the lungs. Surgical excision of these metastases (pulmonary metastasectomy) when possible has become standard practice. We reviewed the published selection and outcome data.

Design: Systematic review of published reports that include survival rates or any other outcome data. Survival data were put in the context of those in a cancer registry.

Setting: Specialist thoracic surgical centres reporting the selection and outcome for pulmonary metastasectomy in 18 follow-up studies published 1991-2010.

Participants: Patients having one or more of 1357 pulmonary metastasectomy operations performed between 1980 and 2006.

Interventions: All patients had surgical pulmonary metastasectomy. A first operation was reported in 1196 patients. Of 1357 patients, $43 \%$ had subsequent metastasectomy, some having 10 or more thoracotomies. Three studies were confined to patients having repeated pulmonary metastasectomy.

\section{Primary and secondary outcome measures:}

Survival data to various time points usually 5 years and sometimes 3 or 10 years. No symptomatic or quality of life data were reported.

Results: About $34 \%$ and $25 \%$ of patients were alive 5 years after a first metastasectomy operation for bone or soft tissues sarcoma respectively. Better survival was reported with fewer metastases and longer intervals between diagnosis and the appearance of metastases. In the Thames Cancer Registry for 19851994 and 1995-2004 5 year survival rates for all patients with metastatic sarcoma were $20 \%$ and $25 \%$ for bone, and for soft tissue sarcoma $13 \%$ and $15 \%$.

Conclusions: The 5 year survival rate among sarcoma patients who are selected to have pulmonary metastasectomy is higher than that observed among unselected registry data for patients with any metastatic disease at diagnosis. There is no evidence that survival difference is attributable to metastasectomy. No data were found on respiratory or any other symptomatic benefit. Given the certain harm associated with thoracotomy, often repeated, better evidence is required.

\section{ARTICLE SUMMARY}

Article focus

- Sarcoma metastases are characteristically blood borne and predominately in the lungs.

- Lung metastases are readily imaged and can be removed, while sparing lung parenchyma, often with minimally invasive techniques.

- Pulmonary metastasectomy for bone and soft tissue sarcoma entered clinical practice about 40 years and has become established as a standard of care.

Key messages

- A systematic review of the literature discovered no randomised trial or any other formal attempt to compare survival following pulmonary metastasectomy with what might have been the outcome in similar patients without this surgery.

- There is no evidence in the literature of palliative benefit from pulmonary metastasectomy.

- Detrimental effects on breathing place a limit on repeated and extensive metastasectomy but no beneficial effects are documented.

Strengths and limitations of this study

- The studies retrieved and systematically reviewed are believed by specialists in sarcoma care to be representative of clinical practice and their experience with management of metastatic sarcoma.

- The data retrieved from clinical follow-up studies and the cancer registry are so different with respect to which patients are included, and the data elements available for analysis, that any comparisons are tenuous.

\section{INTRODUCTION}

Pulmonary metastasectomy is a wellestablished component in the management of sarcoma. Metastases may be confined to the lung where, surrounded by air containing lung, they are readily detected on radiographs and are usually surgically accessible. The Cooperative Osteosarcoma Study Group (COSS) found that, of 202 patients who had 
metastases at diagnosis, $81 \%$ had lung metastases and $62 \%$ only lung metastases. ${ }^{1}$ In an analysis of three European Osteosarcoma Intergroup (EOI) randomised controlled trials of chemotherapy, of 564 patients who had recurrence, $307(54 \%)$ had metastases only in the lung. ${ }^{2}$ Osteosarcoma particularly affects the young, who are better able to withstand surgery and, if they can be cured by eradicating the disease, or their survival is substantially lengthened, there are potentially many years of life expectancy to be restored.

The decision to perform pulmonary metastasectomy is usually now made by specialist sarcoma teams and is based on factors such as the interval since primary surgery, the number and rate of growth of metastases, and their response to chemotherapy. The surgical approach may be videothoracoscopic or by thoracotomy, and surgery may be through staged lateral thoractomies or bilateral through an anterior approach. The pulmonary resections are also 'individualised' depending on the location, size and number of metastases, with an implicit commitment to spare as much lung parenchyma as possible. It may be this degree of variability which makes data tabulation difficult. The authors of the 2011 EOI analysis acknowledged that "Amongst the limitations is the limited information on how the recurrences were treated. However, all patients were treated in experienced sarcoma centres and it is likely that all patients received the best available treatment for their recurrence. This includes, whenever possible, complete resection of a local recurrence and/or surgical treatment of all distant recurrences in case of resectable disease."

In 2006, the UK National Institute for Health and Clinical Excellence (NICE) which issues guidance to the National Health Service in England and Wales, published a manual for commissioners of cancer service on 'Improving Outcomes for People with Sarcoma'. The manual is more about organisation than guidance on clinical practice and states that "The management of chest wall, intrathoracic sarcomas and pulmonary metastases requires a combination of skills available from a sarcoma multidisciplinary team (MDT) and a thoracic surgeon, often combined with plastic surgical reconstructive skills." Included in this guidance is the advice on surveillance for the appearance of pulmonary metastases and states in that context "None of the 21 patients who presented between follow-up visits with symptomatic pulmonary metastases were considered candidates for potentially curative surgical resection of their metastases. Resection of pulmonary metastases was performed for 24 of the 36 patients whose asymptomatic recurrence was discovered by surveillance chest x-ray or staging CT scan" ${ }^{3}$ based on evidence reviewed. ${ }^{45}$ There is evident readiness to operate on asymptomatic pulmonary metastases in sarcoma patients but evidence for the practice, or guidance as to which patients are believed to benefit, cannot be inferred from this practice manual.

Thoracic surgeons are increasingly being asked to remove lung metastases as part of the overall management for a wide range of cancers. In a survey conducted by the European Society of Thoracic Surgeons (ESTS) ${ }^{6}$ practice varied considerably. In particular, there was a wide range of opinions on the weight to be placed on factors known to be associated with survival such as the time elapsed since diagnosis of the primary tumour and the number of metastases seen on imaging. This survey was part of a wider programme of work called The European Society of Thoracic Surgeons Lung Metastasectomy Project. ${ }^{7}$ In the introduction to the published report the leaders of the project concluded "the level of evidence to support current practice is too low to set firm recommendations to the members of ESTS." At the time of writing up The Lung Metastasectomy Project of the ESTS an up-to-date review of metastasectomy for sarcoma was not available and the report went to press without it. We have therefore undertaken a literature search and a systematic review of pulmonary metastasectomy for sarcoma.

\section{MATERIAL AND METHODS \\ Eligibility criteria}

A literature search was conducted according to PRISMA 2009 recommendations. ${ }^{8}{ }^{9}$ We considered eligible all the articles in the English language, from 1990 to the first week of June 2011, which contained at least 20 patients and any data on surgical outcome(s). Reviews and teaching articles which contributed no data for analysis were excluded. Thames Cancer Registry (TCR) data were extracted for all cases of bone and soft tissue sarcoma registered from 1985 to 2008.

\section{Types of participant}

All patients of any age undergoing pulmonary metastasectomy from any type of sarcoma (bone, soft tissue and mixed series) regardless of first time or repeated surgery.

\section{Type of intervention}

First time or repeated metastasectomy from sarcoma.

\section{Information sources}

A Medline search was conducted using OVIDSP interface. Medline web interface at http://www.pubmed.gov was also searched. The TCR data was used as the comparator.

\section{Electronic search}

The search expression used was: (lung.mp) AND (metastasectomy.mp) AND (sarcoma.mp).

\section{Study selection}

One author (MS) evaluated the reports' quality from titles and abstracts identified from the electronic database searches according to the predefined eligibility criteria. The full text articles of studies that potentially met 
the inclusion criteria were retrieved to assess definite eligibility for inclusion.

\section{Data collection process}

The data were extracted by two of the authors (MS and FF) independently and then checked by another author (TT).

\section{Data items}

The selected papers were searched and, where available, data were extracted with respect to:

- Research methodology employed.

- The purpose of the study.

- The patient population from which pulmonary metastasectomy patients were drawn.

- Inclusion and exclusion criteria.

- Demographic data on patients selected and reported.

- The interval between primary surgery and diagnosis and pulmonary metastasectomy.

- Chemotherapy use.

- Surgical approach, whether open or videothoracoscopic.

- Surgical techniques employed.

- Survival data.

- Statistical analyses of factors related to outcome.

- Consideration of second and subsequent metastasectomy operations.

- Symptoms and respiratory performance.

TCR data were extracted for stage, data on interventions, sex ratio, median age and survival.

\section{RESULTS}

The initial search returned 98 articles. In addition, the reference lists of all papers were searched. We retrieved a further 17 articles, to make the total up to 115 having excluded duplicate records by title, authors or DOIs. Sixty-five articles were excluded by title and/or abstract according to the specified criteria. The full text of the remaining 50 articles was retrieved. Of these 32 were excluded because they did not meet the criteria on full text review or because they duplicated data given in other included studies.

We retained 18 articles published since 1990 for inclusion in the systematic review: five report on first and subsequent pulmonary metastasectomy for bone sarcoma, ${ }^{10-14}$ six on soft tissue sarcoma ${ }^{15-20}$ and four on mixed sarcoma series. ${ }^{21-24}$ The information in tables 1-4 are extracted from these 15 studies which include data on the patients' first pulmonary metastasectomy. Three of the 18 are confined to repeat pulmonary metastasectomy. ${ }^{25-27}$ One of these ${ }^{27}$ contained 14 patients rather than the specified minimum of 20 patients but is a further report providing outcomes for repeat metastasectomy in some of the patients reported from the same institution and was therefore included. ${ }^{13}$

With respect to research methodology, there were no randomised controlled trials. There was one comparison study in which patients who had undergone videothoracoscopic resection were matched with patients who had undergone a thoracotomy approach. ${ }^{24}$ There were no protocol-based prospective studies. There was one retrospective cohort study of data obtained from a Cancer Centre's institutional Tumor Registry. ${ }^{11}$ In other reports, cases were identified from databases which were held, as far as we could determine, at an institutional level $^{1012-1720232627}$ or departmental level. ${ }^{18} 19212425$ It appears that many of the clinical data were retrieved by retrospective case note review. A statement in a report from the M.D. Anderson Cancer Centre (MDACC) is probably representative of the approach to data collection: "A prospective surgical database was used to identify metastasectomy patients and missing clinical data were supplemented in a retrospective manner." 23

In most studies, the stated purpose of analysis was to report survival following first ${ }^{10-21} 2324$ or repeated pulmonary metastasectomy. ${ }^{22} \quad 25-27$ In 10 of the 18 reports, statistical analyses were performed to identify patient and tumour characteristics associated with improved survival following first pulmonary metastasectomy. ${ }^{11} 131416181921232526$

The population from which the patients having pulmonary metastases were drawn, is given in seven publications (table 1). ${ }^{10-12} 14151723$ As can be seen from the footnotes to the table, no two denominators are defined in the same way and none are comprehensive at a community level. Some authors give an upper age limit (not more than $55,{ }^{12}$ $40^{14}$ or 20 years $^{11}$ ) but read in context this appears to be to match the data set of operated patients rather than a prior policy. Some series include all sites of primary disease while others are limited to limbs ${ }^{10} 12$ or trunk and limbs. ${ }^{11}$ They variously include all sarcoma patients, ${ }^{23}$ or only those with soft tissue sarcoma (STS). ${ }^{17}$ The proportion of the denominator population recorded as developing pulmonary metastases ranges between $18 \%$ and $50 \%$ while the proportion of those with pulmonary metastases who have an operation to remove them varied from $5 \%$ to $88 \%$. The report with the largest data set $\left(\mathrm{MDACC}^{23}\right)$ reported that only $1 \%$ of sarcoma patients have a pulmonary metastasectomy. We have not found it possible to determine how much of the variation in the recorded data is attributable to varying selection in clinical practice, the different biology of tumours according to histology, tumour site or variation among patients. A large amount of the variation appears to depend on how wide the net is cast in capturing the denominator.

Among these 18 studies of pulmonary metastasectomy for sarcoma the inclusion criteria are much as those proposed by Thomford $^{28}$ that the cancer at the primary site was eradicated, controlled or amenable to

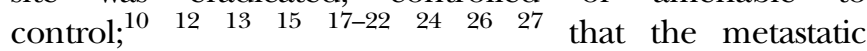
lung disease was amenable to complete resection; ${ }^{10} 11 \quad 13 \quad 15 \quad 18-2124 \quad 2627$ that there was no metastatic disease elsewhere; ${ }^{10} 12 \quad 13 \quad 15 \quad 17-22 \quad 24 \quad 26 \quad 27$ and that the patient was expected to withstand the loss of lung tissue necessary to give clearance. ${ }^{10-12} \quad 15 \quad 17-22 \quad 24 \quad 26 \quad 27$ In 
Table 1 Data from reports providing the number of patients from which the study population was derived

\begin{tabular}{|c|c|c|c|c|c|c|c|c|c|}
\hline Publication & Histology & $\begin{array}{l}\text { Start } \\
\text { date }\end{array}$ & $\begin{array}{l}\text { End } \\
\text { date }\end{array}$ & $\begin{array}{l}\text { All registered } \\
\text { sarcoma } \\
\text { patients (A) }\end{array}$ & $\begin{array}{l}\text { Patients with } \\
\text { pulmonary } \\
\text { metastases (B) }\end{array}$ & $\begin{array}{l}\text { Pulmonary } \\
\text { metastasectomy as } \\
\text { reported in cited } \\
\text { papers in systematic } \\
\text { review (C) }\end{array}$ & $\begin{array}{l}\text { Proportion of } \\
\text { sarcoma } \\
\text { patients with } \\
\text { pulmonary } \\
\text { metastases } \\
\text { (=B/A) }(\%)\end{array}$ & $\begin{array}{l}\text { Proportion of patients } \\
\text { with pulmonary } \\
\text { metastases who have } \\
\text { metastasectomy (data } \\
\text { as in reports) (=C/B) (\%) }\end{array}$ & $\begin{array}{l}\text { Proportion of all } \\
\text { sarcoma patients } \\
\text { who have } \\
\text { pulmonary } \\
\text { metastectomy } \\
\text { (=C/A) (\%) }\end{array}$ \\
\hline $\begin{array}{l}\text { Antunes } \\
1999\end{array}$ & Bone & 1989 & 1997 & $198^{*}$ & & 31 & & & 16 \\
\hline $\begin{array}{l}\text { Harting } \\
2006\end{array}$ & Bone & 1980 & 2000 & $272 \dagger$ & $137 \ddagger$ & 99 & 50 & 72 & 36 \\
\hline $\begin{array}{l}\text { Briccoli } \\
2010\end{array}$ & Bone & 1985 & 2005 & $1197 \S$ & 369ף & 323 & 31 & 88 & 27 \\
\hline $\begin{array}{l}\text { Buddingh } \\
2009\end{array}$ & Bone & 1990 & 2008 & $197^{\star \star}$ & 88†† & 56 & 45 & 64 & 28 \\
\hline Gadd 1993 & STS & 1983 & 1990 & 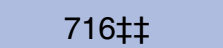 & $135 \S \S$ & 78 & 19 & 58 & 11 \\
\hline $\begin{array}{l}\text { Rehders } \\
2007\end{array}$ & STS & 1991 & 2002 & 678ๆר & $121^{\star \star *}$ & 61 & 18 & 50 & 9 \\
\hline $\begin{array}{l}\text { Blackmon } \\
2009\end{array}$ & Mixed & 1998 & 2006 & 15744††† & 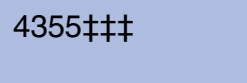 & 234 & 28 & 5 & 1 \\
\hline \multicolumn{10}{|c|}{ 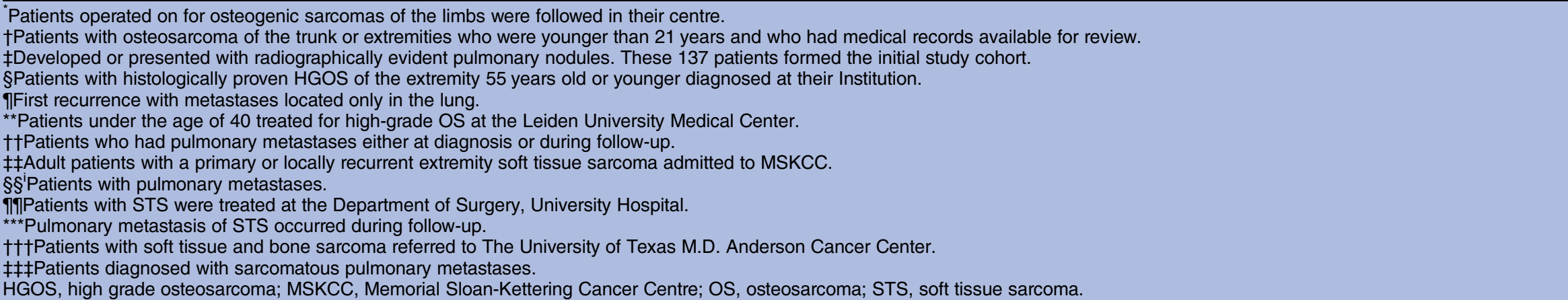 } \\
\hline
\end{tabular}


Table 2 Summary data on 15 papers reporting on series of patient undergoing a first pulmonary metastasectomy operation for sarcoma

\begin{tabular}{|c|c|c|c|c|c|c|c|c|c|}
\hline Author & $\begin{array}{l}\text { Sarcoma patients } \\
\text { who have } \\
\text { pulmonary } \\
\text { metastasectomy } \\
\text { (N) }\end{array}$ & $\begin{array}{l}\text { Age } \\
\text { mean } \\
\text { (years) }\end{array}$ & $\begin{array}{l}\text { Age } \\
\text { range } \\
\text { (years) }\end{array}$ & $\begin{array}{l}\text { Sex } \\
\text { males }\end{array}$ & $\begin{array}{l}\text { Sex } \\
\% \\
\text { male }\end{array}$ & $\begin{array}{l}\text { Median } \\
\text { interval } \\
\text { between } \\
\text { primary and } \\
\text { metastases } \\
\text { (months) }\end{array}$ & $\begin{array}{l}\text { Range } \\
\text { (months) }\end{array}$ & $\begin{array}{l}\text { Mean } \\
\text { number } \\
\text { of mets } \\
\text { resected }\end{array}$ & Range \\
\hline \multicolumn{10}{|l|}{ Bone } \\
\hline Antunes 1999 & 31 & 25 & $10-54$ & 21 & 68 & 22 & $4-122$ & 3.2 & $1-8$ \\
\hline Harting 2006 & 99 & 13.9 & \pm 4.2 & 67 & 68 & 0 in $17 \%$ & 0-NF & & $1 \rightarrow 10$ \\
\hline Briccoli 2010 & 323 & 16 & $4-55$ & 201 & 62 & NF & & NF & NF \\
\hline Chen 2008 & 23 & 19 & $6-68$ & 15 & 65 & 19 & $0-108$ & 5.0 & \\
\hline Buddingh 2010 & 56 & NF & NF & 40 & 71 & NF & & & \\
\hline \multicolumn{10}{|l|}{ Soft tissue } \\
\hline Gadd 1993 & 78 & $(55)^{*}$ & $17-85$ & NF & & 14 & $1-152$ & NF & NF \\
\hline Smith 2009 & 94 & 49 & $9-75$ & 47 & 50 & 15 & 0-NF & 2.5 & $1-105$ \\
\hline Rehders 2007 & 61 & 42 & $18-47$ & 33 & 54 & 21 & $0-3$ & 5.0 & $1-48$ \\
\hline Garcia Franco 2009 & 22 & 41 & $13-82$ & 10 & 45 & 18 & $5-84$ & & \\
\hline Sardenberg 2010 & 77 & 45 & NF & 37 & 48 & NF & & 3.5 & \\
\hline Chen 2009 & 23 & 53 & $15-86$ & 12 & 52 & NF & $0-168$ & & \\
\hline \multicolumn{10}{|l|}{ Mixed } \\
\hline Snyder 1991 & 34 & 23 & NF & 20 & 59 & 19 & $<6->24$ & 11 & NF \\
\hline Blackmon 2009 & 234 & $<50^{\star}$ & & 123 & 53 & Varied & NF & NF & NF \\
\hline Gossot 2009 & 60 & 40 & & 34 & 57 & 18 & NF & NF & NF \\
\hline Garcia franco 2010 & 52 & 20 & $5-74$ & 31 & 60 & 20 & $5-189$ & NF & NF \\
\hline
\end{tabular}

individual instances authors specified that there should be no mediastinal or chest wall involvement; ${ }^{17}$ absence of pericardial or pleural effusions; ${ }^{12}$ that the overall operative risk was acceptable; ${ }^{26}$ or that there was no other available more effective treatment. ${ }^{19}$ In one report, increased

Table 3 The proportion of patients who have second or subsequent metastasectomy

\begin{tabular}{lccl}
\hline Series & First N & Second N & Multiple (\%) \\
\hline Rehders 2007 & 61 & 13 & 21 \\
Antunes 1999 & 31 & 8 & 26 \\
Garcia franco 2010 & 52 & 16 & 31 \\
Garcia Franco 2009 & 22 & 7 & 32 \\
Chen (EJSO) 2009 & 23 & 8 & 35 \\
Smith 2009 & 94 & 33 & 35 \\
Briccoli 2005 & 267 & 94 & 35 \\
Briccoli 2010 & 323 & 122 & 38 \\
Buddingh 2010 & 56 & 26 & 46 \\
Sardenberg 2010 & 77 & 37 & 48 \\
Gossot 2009 & 60 & 33 & 55 \\
Blackmon 2009 & 234 & 141 & 60 \\
Chen (EJCTS) 2008 & 23 & 14 & 61 \\
Snyder 1991 & 34 & 28 & 82 \\
\hline
\end{tabular}

This does not include staged bilateral thoracotomies which are regarded as a single intervention.

Reports are ranked according to the proportion having second and subsequent metastasectomy interventions. Sequential-staged operations (eg, lateral thoracotomies planned with an interval of 1-3 weeks) are considered by the authors as a single episode of treatment. size on chemotherapy was allowable, but not an increase in the number of metastases. ${ }^{24}$ One study with five subgroups gave group-by-group criteria which, read in context, appeared to be defined after exploration of the available data to facilitate analysis and reporting. ${ }^{23}$ Criteria for inclusion or exclusion in the metastasectomy cohort were not found in three studies. ${ }^{14} 1625$

Data are given in table 2 for the 15 studies which include data on the first pulmonary metastasectomy, for a total of 1168 patients. The average age of bone sarcoma patients was 17 years based on 377 patients in four studies with calculable data, ${ }^{1012} 13$ excluding the reports limited to patients aged $<21$ years ${ }^{11}$ or $<40$ years. ${ }^{14}$ For soft tissue sarcoma the average age was 46 based on five studies including 277 patients ${ }^{16-20}$ excluding a study where median and range were given. ${ }^{15}$

Male sex was predominant in bone sarcoma $(65 \%$ of 532 patients) but not in soft tissue sarcoma reports (50\% of 277 patients). These differences in age and sex preclude meaningful amalgamation of outcome data following pulmonary metastasectomy for bone and soft tissue sarcoma.

The interval between resection of the primary and first pulmonary metastasectomy was provided in $9 / 15$ reports and was highly variable as can be seen from table 2. There is a degree of consistency in the median interval of 1-2 years but half of the authors providing data, operated on synchronous metastases (5 of 10). Repeat metastasectomy was performed in $43 \%$ of 
Table 4 Surgical approaches and resection techniques in reports of first time pulmonary metastasectomy

\begin{tabular}{|c|c|c|}
\hline Report & Surgical approach & Surgical technique \\
\hline Snyder 1991 & $\begin{array}{l}\text { Thoractomy } \\
\text { Bilateral disease-staged thoracotomy, 1-2 weeks interval 16/34 }\end{array}$ & Enucleation \\
\hline Antunes 1999 & $\begin{array}{l}\text { Thoracotomy } 30 / 31 \\
\text { Median sternotomy } 1 / 31\end{array}$ & $\begin{array}{l}\text { Enucleation } \\
\text { Wedge resection } \\
\text { Lobectomy }\end{array}$ \\
\hline Harting 2006 & $\begin{array}{l}\text { Thoracotomy, staged or simultaneous bilateral thoracotomies } \\
\text { Median sternotomy }\end{array}$ & \\
\hline Briccoli 2010 & $\begin{array}{l}\text { Thoracotomy } \\
\text { Bilateral thoracotomies }\end{array}$ & $\begin{array}{l}\text { Wedge resection } \\
\text { Lobectomy } \\
\text { Pneumonectomy }\end{array}$ \\
\hline Garcia Franco & Thoracotomy $30 / 52$ & Wedge $44 / 52$ \\
\hline 2010 & $\begin{array}{l}\text { Sequential bilateral thoracotomy } 7 / 52 \\
\text { VATS } 10 / 52 \\
\text { Clamshell } 5 / 52\end{array}$ & $\begin{array}{l}\text { Lobectomy } 6 / 52 \\
\text { Exploratory thoracotomies } 2 / 52^{*}\end{array}$ \\
\hline Chen 2008 & Thoracotomy & $\begin{array}{l}\text { Wedge } 22 / 23 \\
\text { Lobe } 1 / 23\end{array}$ \\
\hline Smith 2009 & & $\begin{array}{l}\text { Wedge } 74 / 94 \\
\text { Lobectomy } 17 / 94 \\
\text { Pneumonectomy } 3 / 94 \\
\text { Resection of other thoracic disease } 16 / 94\end{array}$ \\
\hline Rehders 2007 & $\begin{array}{l}\text { Thoracotomy } 29(48) \\
\text { Bilateral thoracotomy, two sessions } 10(16) \dagger \\
\text { Median sternotomy } 22(36)\end{array}$ & $\begin{array}{l}\text { Wedge resection } 52(85) \\
\text { Lobectomy } 9(15)\end{array}$ \\
\hline Garcia Franco & Thoracotomy 19 & Wedge 19 \\
\hline 2009 & $\begin{array}{l}\text { VATS } 2 \\
\text { Sternotomy } 1\end{array}$ & Lobectomy 3 \\
\hline Sardenberg 2010 & $\begin{array}{l}\text { Thoracotomy } \\
\text { Staged bilateral thoracotomy }\end{array}$ & Complete resection with $10 \mathrm{~mm}$ margin \\
\hline $\begin{array}{l}\text { Chen (EJSO) } \\
2009\end{array}$ & & $\begin{array}{l}\text { Wedge resection } 21 / 23 \\
\text { Lobectomy } 1 / 23 \\
\text { Pneumonectomy } 1 / 23\end{array}$ \\
\hline Gossott 2009 & $\begin{array}{l}\text { Thoracotomy } 29 \\
\text { VATS } 31 \\
\text { In a comparative study of the two approaches }\end{array}$ & \\
\hline
\end{tabular}

patients based on 14/18 reports in which the data could be extracted (table 3).

Chemotherapy was frequently used but schedules were variable both within and between publications. Some authors stated that preoperative and/or postoperative chemotherapy was given routinely in all cases ${ }^{10212627}$ but more often the practice varied. ${ }^{11-14} 161821$ One paper states "The only constant was that when the disease-free interval was $<2$ years with a single lung metastasis, no chemotherapy was added to surgery" and another that it was at the discretion of the oncologist. ${ }^{19}$ One group used chemotherapy preoperatively only when there were six or more metastases. ${ }^{17}$ It was also implicit in the text of several papers that response to chemotherapy was part of the clinical evidence used to help select patients for surgery; non-responding and progressing patients were less likely to be selected for pulmonary metastasectomy and this information is not necessarily explicit in the report. This statement in the report from the
MDACC is representative of this approach: "Those who developed metastatic disease early with multiple pulmonary nodules were treated initially with chemotherapy to determine the pace of disease progression, if any, on treatment. Patients responding to chemotherapy, those with stable disease, and those with slow progression were referred for resection while those with rapidly progressive metastatic disease received alternative chemotherapy treatment." ${ }^{23}$

Whether videoscopic or open surgery was used, and if open through what incision, and the surgical technique used to resect the metastases, are summarised in table 4 for 12/15 papers including data on first metastasectomy operations. $^{10-13}$ 16-21 24 The remaining 3 of the 15 studies were not explicit with respect to the surgical approach. In the more common surgery for carcinoma metastasised to the lung, lymphadenectomy has become an important consideration. ${ }^{29}$ In these reports concerning sarcoma patients, hilar nodes were not routinely 
dissected $^{19}$ or maybe dissected 'when necessary'. ${ }^{12}$ This avoidance of lymphatic resection appears to be linked to the lower rate of lymphatic spread in sarcoma compared with other thoracic malignancy in which further spread from the metastases to mediastinal lymph nodes is frequent. ${ }^{29}$

There is a strong evident preference for open surgery (96\% of patients had a thoracotomy of some form) with considerable emphasis placed by several authors on the importance of manual palpation of the lung ${ }^{10-12} 16172022$ which cannot be achieved through a purely videoscopic approach. One study specifically addressed the question for whether the less invasive thoracoscopic approach might be as effective ${ }^{24}$ and it was concluded that it might be an option if there are no more than two metastases but this was not derived from data analysis presented in the publication. The general use of thoracotomy, often bilateral and repeated metastasectomy in $43 \%$ of patients overall represents a high treatment burden for patients (tables 3 and 4).

TCR data for sarcoma were studied to provide some context to the overall survival rates of patients with sarcoma (figure 1). The Registry has employed its own four-level staging system since 1960 and stages around $60 \%$ of all solid tumours. The classification system uses information in the patients' notes to determine if the disease is local (stage 1), has extension beyond the organ of origin (stage 2), has regional lymph node involvement (stage 3) or has metastasised (stage 4).
Survival data by stage for two complete decades 1985-1994 and 1995-2004 for both bone and soft tissue sarcoma are provided in figure 1. For patients entered as stage 4 bone sarcoma (metastatic disease at the time of registration) in those two decades 5-year survival of $20 \%$ and $25 \%$ are recorded for bone sarcoma and $13 \%$ and $15 \%$ for soft tissue sarcoma.

The Registry does not include full data on treatment but does provide data on the highest surgery code. These are presented in an abbreviated form in table 5 . According to the selection criteria set out above, since the stated first criterion for pulmonary metastasectomy was that a radical operation had been successful at the primary cancer site, it is among the $8 \%$ of bone sarcoma patients and $21 \%$ of soft tissue sarcoma patients that pulmonary metastasectomy patients would be found. Summary data of sex distribution and the median age for patients in two completed decades (1985-1994 and 1995-2004) with bone and STS are in table 6.

Five-year survival data are plotted against publication date (figure 2) and the size of the series (figure 3) for 14 of these 15 studies where the data are given, to allow for visual inspection of time or case volume. Three-year and/or 5-year survival for the 15 studies including first (and subsequent) metastasectomy data are plotted in figure 4.

Five-year survival data are set out in table 7 sorted by tumour type from 14 of the 15 studies including first (and subsequent) metastasectomy data. Together these

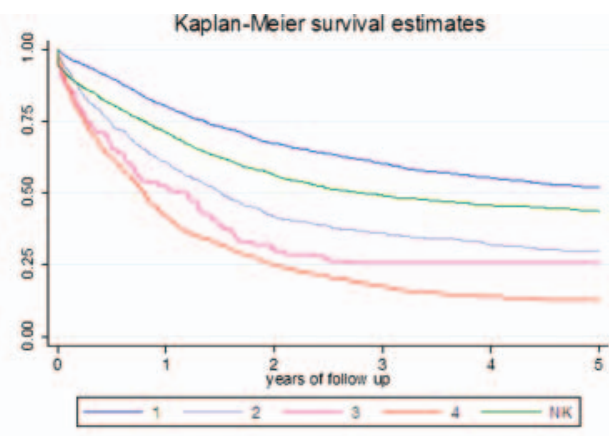

STS 1985-1994 Stage 4 YYS $12.6 \%(\mathrm{~N}=689)$

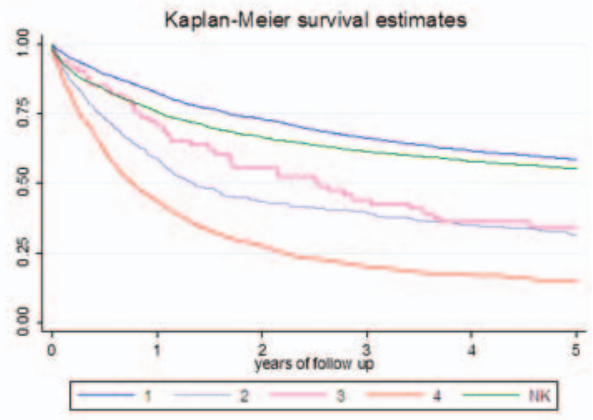

STS $1995-2004$ Stage 4 5YS $14.9 \%(\mathrm{~N}=1052)$

Figure 1 Thames Cancer Registry data. Kaplan Meier survival plots by stage for decades 1985-1994 (above) and 1995-2004 (below) for bone (left) and soft tissue sarcoma (right). Stage 4 (ie, metastasised at the time of diagnosis/registration) in red. 
Table 5 Highest Surgery Code of Thames Cancer Registry sarcoma patients 1985-2008

\begin{tabular}{|c|c|c|c|c|}
\hline & \multicolumn{2}{|l|}{ Bone } & \multicolumn{2}{|l|}{ STS } \\
\hline & $\overline{\mathbf{N}}$ & Percentage & $\overline{\mathbf{N}}$ & Percentage \\
\hline Total removal of organ, or operation stated to be radical & 145 & 8 & 3203 & 21 \\
\hline Partial or debulking operations on the primary tumour & 648 & 35 & 4935 & 32 \\
\hline Lymphadenectomy & 2 & 0.1 & 171 & 1 \\
\hline Non-tumour removing surgical treatment & 160 & 9 & 245 & 2 \\
\hline Haematological procedure (eg, bone marrow transplant) & 2 & 0.1 & 19 & 0.1 \\
\hline Investigative procedure only & 298 & 16 & 2072 & 14 \\
\hline Type of surgery not known & 11 & 1 & 59 & 0.4 \\
\hline \multirow[t]{2}{*}{ No surgery recorded } & 581 & 31 & 4559 & 30 \\
\hline & 1847 & 100 & 15263 & 100 \\
\hline
\end{tabular}

provide data on 1196 patients having metastasectomy from as early as $1976^{16}$ to as recently as $2008 .{ }^{14}$ Overall about a third of patients who have had pulmonary metastasectomy for bone sarcoma and about a quarter who have had pulmonary metastasectomy for STS survive beyond 5 years. TCR five-year survival data for two complete decades 1985-1994 and 1995-2004 are included in the table to provide a reference measure of survival in all sarcoma patients in the registry who were classified as stage 4 , that is, sarcoma metastasised at presentation/registration. Direct comparison cannot be made but it is a reminder that an implicit assumption that the 5-year survivals of the patients in the pulmonary metastasectomy series would have approached zero would be incorrect.

We can reasonably deduce that

1. Five-year survival after pulmonary metastasectomy is not necessarily attributable to the metastasectomy.

2. Five-year survival does not equate to cure since there are 5-year survivors with metastatic disease.

Five-year survival from 14 of the 15 studies reporting first (and subsequent) pulmonary metastasectomy operations. They are grouped by sarcoma type and then by mid-year of the series to aid visual inspection for time trends. TCR 5-year survival data for stage 4 patients are provided for two complete decades of data overlapping the reported series. These TCR patients all had metastases at presentation but not necessarily lung or lung only.

Table 6 Survival data, sex ratio and median age of patients in Thames Cancer Registry for two decades 1985-1994 and 1995-2004

\begin{tabular}{lllll}
\hline Year & Cases & $\begin{array}{l}\text { M/F } \\
\text { ratio }\end{array}$ & $\begin{array}{l}\text { Median } \\
\text { age }\end{array}$ & $\begin{array}{l}\text { Five-year } \\
\text { survival (\%) }\end{array}$ \\
\hline $\begin{array}{c}\text { Bone } \\
1985-1994\end{array}$ & 762 & 1.31 & 35 & 20 \\
$\begin{array}{c}1995-2004 \\
\text { Soft tissue }\end{array}$ & 709 & 1.35 & 33 & 25 \\
$1985-1994$ & 5615 & 0.98 & 56 & 13 \\
$1995-2004$ & 6256 & 0.82 & 58 & 15 \\
\hline
\end{tabular}

Data are not available in the publications concerning the fate of patients beyond 5 years and there are no narrative accounts of the clinical course of these patients. However, a number of the authors include, in their narrative, a statement of belief in cure for patients who have recurred in the lung or that their surgery has curative intent $^{12} 141617192425$ and the phrase "potentially curative resection' is included in NICE guidance. ${ }^{3}$ Illustrative statements from recent publications are these from 2009 and 2010

Given the lack of effective systemic therapies, PM remains the only potentially curative treatment for STS lung metastases as long as all known disease can be completely resected with negative margins. ${ }^{16}$

We demonstrate that after repeated metastasectomies, a subset of patients can be cured. ${ }^{14}$

Other authors explicitly state the improbability of cure attributable to pulmonary metastasectomy. Antunes writes "The 5-year survival may reach 50\%, although true cure is extremely rare, the majority of patients eventually dying of the disease." ${ }^{10}$ And Sardenberg et al state "It should be emphasised that surgery does not change the biology of the tumor or the metastatic process, and a definitive cure for most patients represents the combination of host histology, tumor spread, response to

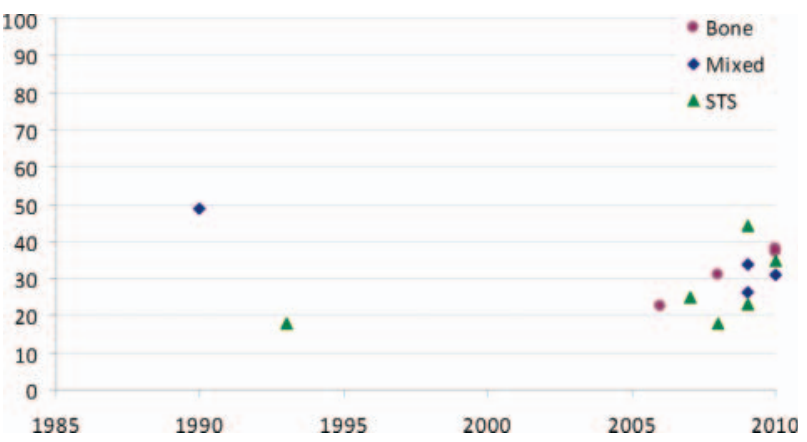

Figure 2 Five-year survival rates plotted against the publication date. 


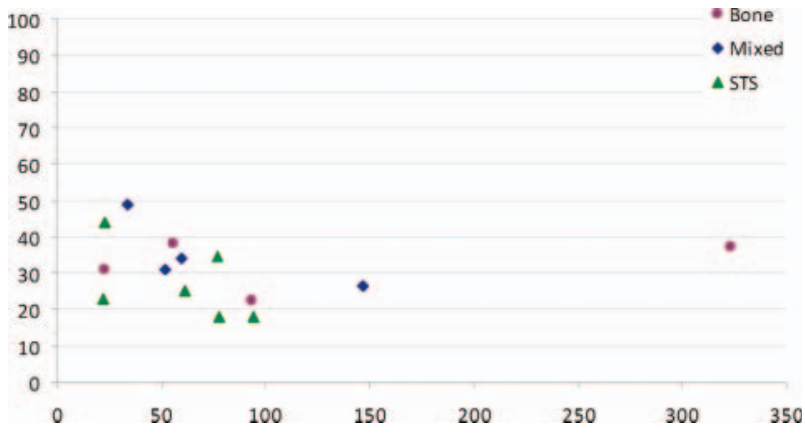

Figure 3 Five-year survival rates plotted against the size of the series.

systemic therapy, and surgical resection, which together render the patient free of disease."19

Several reports include multivariate analysis to seek factors that might determine a greater or lesser survival rate. The interval between diagnosis or resection of the primary cancer and the metastasectomy surgery is the commonest factor reported as being significant $^{11} 181921232526$ survival usually being better if the interval was 12 months or longer. Fewer metastases was also associated with better survival ${ }^{13} 14 \quad 181923252630$ most commonly at a number of about three or fewer. Female $\operatorname{sex}^{14} 16$ was also favourable. Patients in whom there was substantial necrosis following chemotherapy survived longer. ${ }^{10} 111422$

No data were found regarding respiratory function or symptoms in any of the 18 reports. Where mention was made of respiratory function in the text, it was related to the decision to operate. Several authors explained that a point had been, or might be reached, where respiratory function or respiratory reserve precluded further metastasectomy. No measurement of this or its consequences for the patients was provided in any report.

\section{DISCUSSION}

A major limitation, when interpreting reports of pulmonary metastasectomy for sarcoma, is the absence of control data. It is usual in surgery to rely heavily on

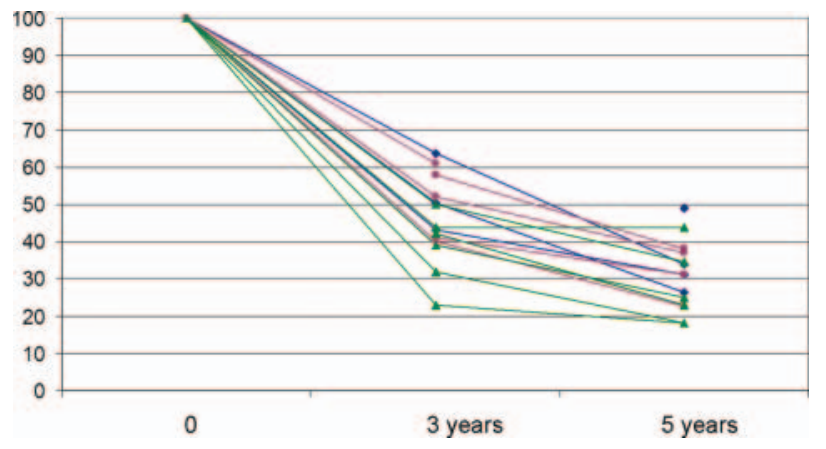

Figure 4 Three-year and 5-year survival rates from publications in table 6 (bone sarcoma red, soft tissue sarcoma green and mixed series blue). evidence from case series, either in the form of retrospective case note reviews or less commonly prospective cohort studies. When there is a clear temporal and mechanistic relationship between cause and effect, and the signal is evident from the noise, observational studies often provide sufficient evidence. ${ }^{31}$ The simple evidence of cause and effect cannot be invoked where there is a widely variable time course and multimodal treatments as is the case in protracted, repeated and multimodal treatment of sarcoma.

Efficacy, effectiveness and cost effectiveness are different measures of the attributes of a treatment. Pulmonary metastasectomy has been shown to be efficacious in that complete macroscopic clearance has been achieved; in appropriately selected cases, R0 resection of all known pulmonary metastases can be consistently accomplished. Whether pulmonary metastasectomy is effective in prolonging life requires proof that survival has been extended, by metastasectomy, beyond that which would have occurred without pulmonary metastasectomy. Cost-effectiveness requires, in addition to survival, measures of health gained, measures of health lost due to death and complications, and for these to be costed in comparison with any alternatives, including no treatment. This third measure, estimation of cost-effectiveness is outside the scope of this review and depends on first establishing effectiveness.

Evaluation of the effectiveness in preventing or postponing death by pulmonary metastasectomy is the common objective in these clinical reports. The existing practice is believed to be effective based on repeated experience worldwide for over 40 years. In 1971, thoracic surgeons at Memorial Sloane-Kettering reported on 22 patients with treated osteogenic sarcoma in whom they performed lung resections. ${ }^{32}$ The meticulous case by case communication of that experience merits revisiting (figure 5).

In the discussion that followed Beattie modestly states:

We reported these data with some reluctance, since they really constitute a progress report on a clinical research project underway at Memorial Hospital. We used osteogenic sarcomas because they are such serious tumors. There are occasional spontaneous regressions and good results; but you saw in the figures Dr Martini showed that with amputation we have had a $17 \%$ five-year cure rate. Of the $83 \%$ of patients who died, $5 \%$ lived 3 years. Very occasionally a patient would go on longer before dying. ${ }^{32}$

Twenty years later ${ }^{33}$ Beattie reported further

Twenty-year follow-up reveals that at least four of the six survivors at 10 years survived more than 19 years; one was lost to follow-up. The patient who died of metastatic osteogenic sarcoma more than 19 years after her first thoracotomy had a total of nine thoracotomies.

An implicit assumption is embedded in many subsequent reports that none of these patients would have lived beyond 5 years without metastasectomy. There are 
Table 7 Five-year survival and Thames Cancer Registry (TCR) summary data

\begin{tabular}{|c|c|c|c|}
\hline Author & $\begin{array}{l}\text { Sarcoma patients who have } \\
\text { pulmonary metastasectomy (N) }\end{array}$ & $\begin{array}{l}\text { Five-year survival } \\
\text { where provided (\%) }\end{array}$ & $\begin{array}{l}\text { Middle date of metastasectomy } \\
\text { series and date ranges for TCR }\end{array}$ \\
\hline \multicolumn{4}{|l|}{ Bone } \\
\hline Harting 2006 & 93 & 23 & 1991 \\
\hline Briccoli 2010 & 323 & 37 & 1996 \\
\hline Chen (EJCTS) 2008 & 23 & 31 & 1999 \\
\hline Buddingh 2010 & 56 & 38 & 2000 \\
\hline TCR & & 20 & 1985-1994 \\
\hline TCR & & 25 & 1995-2004 \\
\hline \multicolumn{4}{|l|}{ Soft tissue } \\
\hline Gadd 1993 & 78 & 18 & 1987 \\
\hline Smith 2009 & 94 & 18 & 1989 \\
\hline Rehders 2007 & 61 & 25 & 1997 \\
\hline Sardenberg 2010 & 77 & 35 & 1999 \\
\hline Chen (EJSO) 2009 & 23 & 44 & 1999 \\
\hline Garcia Franco 2009 & 22 & 23 & 2002 \\
\hline TCR & & 13 & 1985-1994 \\
\hline TCR & & 15 & 1995-2004 \\
\hline \multicolumn{4}{|l|}{ Mixed } \\
\hline Snyder 1991 & 34 & 49 & 1984 \\
\hline Garcia franco 2010 & 52 & 31 & 2002 \\
\hline Blackmon 2009 & 234 & 26 & 2003 \\
\hline Gossot 2009 & 60 & 34 & 2004 \\
\hline
\end{tabular}

other reasons, apart from having had pulmonary metastasectomy, for patients with pulmonary metastatic disease to be alive at and beyond 5 years. These patients are carefully selected and although it is not possible to put a reliable figure on it, they are a minority of all patients with the disease (table 1$).^{2}$ It is appropriate to select patients for surgery and yet comments such as "survival of (surgically treated) patients was significantly better than of patients ineligible for metastasectomy, $\mathrm{p}<0.00001 " 14$ is not an appropriate or meaningful statistical comparison: the difference is evident but how much is due to the selection and how much to the surgery, cannot be determined.

The identifiable factors for the selection of suitable patients include fewer metastases and a longer interval between the diagnosis and treatment of the primary and the resection of pulmonary metastases. ${ }^{34} 35$ Others which appear in some analyses are tumour doubling time and the size of the nodule(s) which under surveillance is a proxy for rate of growth. These are prognostic features for survival under any circumstance. We also know from the TCR data that there are $20-25 \%$ of patients with osteosarcoma and about $15 \%$ with soft tissues sarcoma, with metastases at the time of registration, who are alive beyond 5 years (tables 6 and 7 ). The narrative accounts record that there are some natural long-term survivors: "one patient not operated on remains alive 18 years after not having surgery." 14 "Long-term survivors appear to belong to a subset of patients with indolent, lung-only disease." 36 These natural survivors, who are likely to have slower progression, and fewer metastases, are likely to be disproportionately frequent among patients selected for metastasectomy ${ }^{37}$ for the selection process is not random as illustrated in figure 6. More than 30 years ago Aberg first proposed that selection might be the major factor determining survival after pulmonary metastasectomy $^{38}$ and returned to this question in $1997 .{ }^{39}$ It is of note that none of the authors cite Aberg. It is known that 'citation distortions create unfounded authority' ${ }^{40}$ which has been confirmed in the context of metastasectomy by a citation network analysis. ${ }^{41}$

In fact, the effect of selection may easily be underestimated. Multivariable analysis cannot detect more than a limited number of factors in these relatively small series. All of these factors may exhibit covariance and they are all indices of the relative aggressiveness of a cancer. Failure for one or more of these factors to reach significance in any particular Cox model does not refute the overall finding. Furthermore, if the knowledge of previous finding leads to the exclusion of some patients, the range of that variable is reduced and it is less likely to be found in subsequent analyses. ${ }^{42}$

In this group of young and therefore physically resilient patients there seems to be a strong desire to never say no, and to push the boundaries for selection for metastasectomy. It is well established that patients with more metastases are unlikely to live long after metastasectomy. Nevertheless, there is no apparent upper limit in many of the reports nor was there for $85 \%$ of surgeons in the ESTS survey. ${ }^{6}$ Among the reports of pulmonary metastasectomy in the present systematic review some surgeons report very high numbers of metastases resected. For example "The authors have removed as many as 80-100 nodules during a single thoracotomy"22 


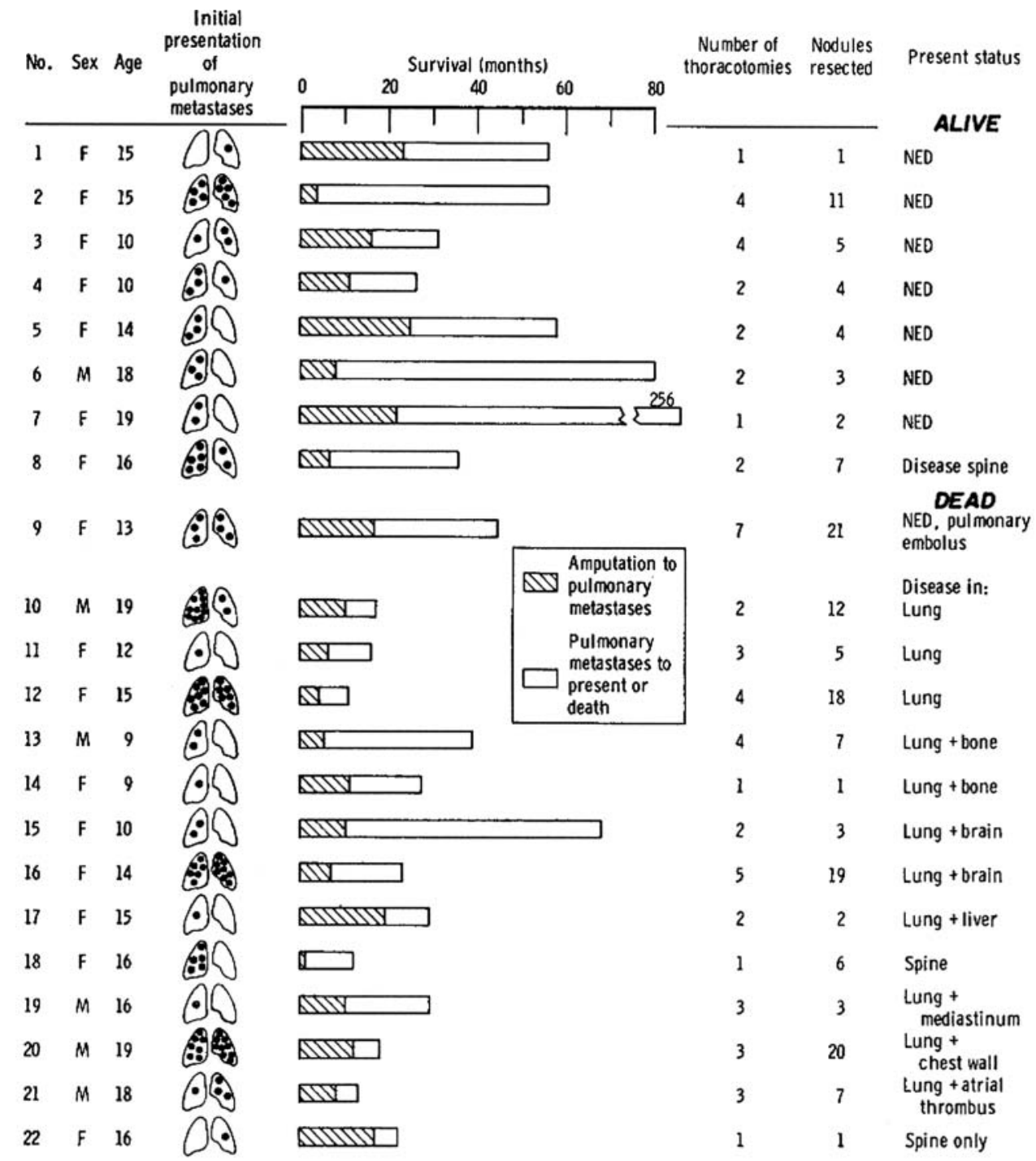

Summary of data on 22 patients with osteogenic sarcoma. (NED $=$ no evidence of disease.)

Figure 5 The full display of essential features of the patients and their survival from primary resection to metastasectomy and subsequently. From Martini et al. ${ }^{32}$

and in the COSS report "The highest number of pulmonary nodules surgically removed was $250 " 1$ are out of line with the observational evidence that above a count of relatively few metastases, outcomes are too poor to justify this surgery. Maybe these high numbers reflect the observation that the preoperative count of nodules underestimates the true extent of the disease "It is interesting that despite the presence of only three or four nodules on many CT scans, up to 50 or more nodules were found and removed in a number of these patients." ${ }^{\prime 2}$ The issue of the relative reliability of modern imaging versus surgeons' palpation of the lung has been considered elsewhere with varying conclusions. ${ }^{434}$

The extent of necrosis caused by chemotherapy evident in the excised nodule was found to be a favourable feature for survival. ${ }^{10}$ The clinical response or failure to respond to chemotherapy was given as factor in selection in several series. Both of these observations are evidence that chemotherapy is having an effective in these patients and has had a demonstrable effect on their disease. Why then should a survival difference be attributed to the surgery?

There is a firm belief that if sarcoma recurs in the lungs, and the patient is still within the criteria for resection, further resections should be performed. "The authors concluded that patients persistently free of the primary osteosarcoma who developed recurrent resectable metastatic disease of the lung should be considered for reoperation a second, third, or fourth time, as these patients had similar DFI curves after five years." ${ }^{26}$ This belief is supported by what might be inappropriate data interpretation. Consider these statements for example: "Prognostic factors for increased survival included 3 or 


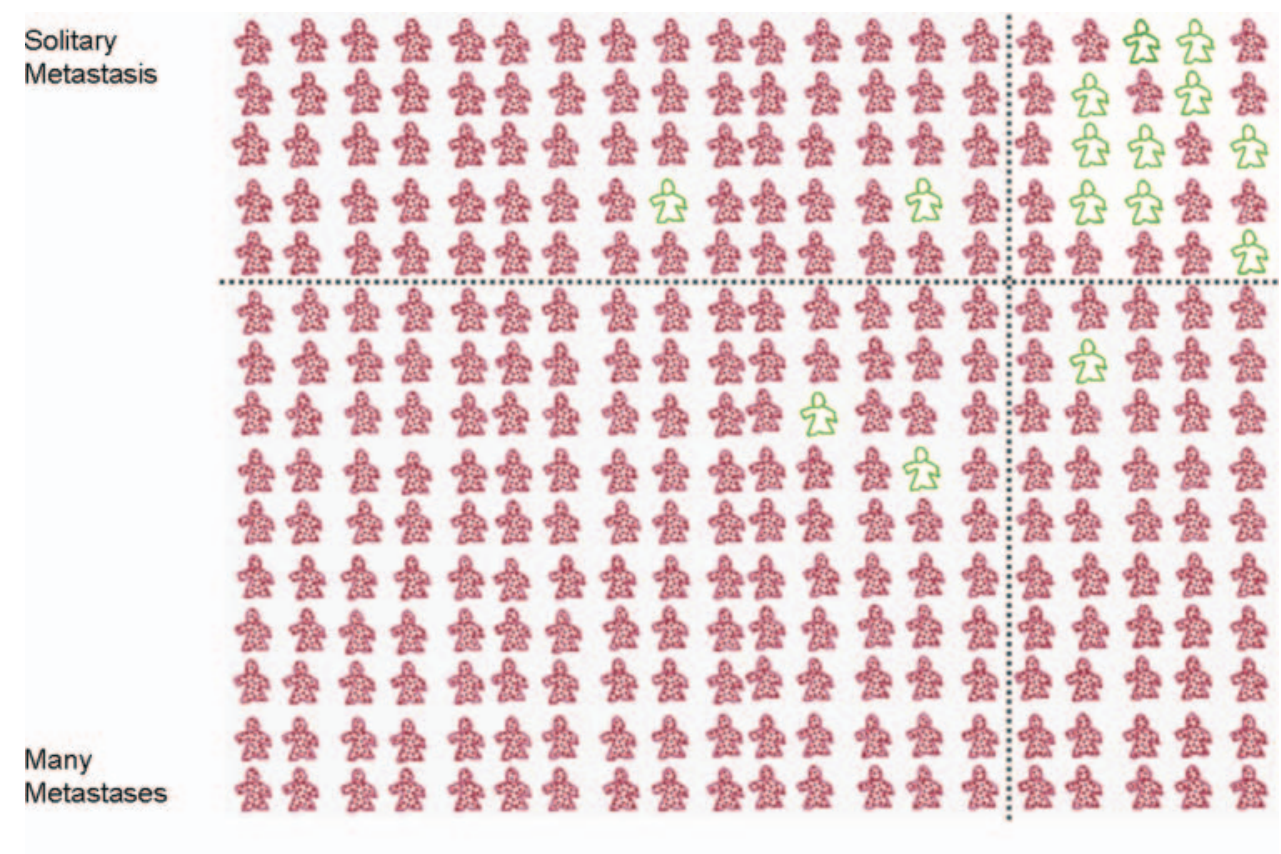

Increasing interval between 10 diagnosis and appearance of pulmonary metastases

Figure 6 A conservative estimate of natural 5-year survivors is set at 5\% (15/300 in this depiction) and they are in green. Ranking patients on the $Y$ and $X$ axes from least to most favourable based on fewer metastases and longer interval since diagnosis might have the effect of clustering these natural survivors as shown. If selection for surgery is also based on these factors, it might be the selection rather than the surgery which is associated with a higher than anticipated survival rate shown here as $10 / 25$ or $40 \%$.

greater redo pulmonary operations'; ${ }^{23}$ "patients with complete resection for recurrent pulmonary metastasis show a significantly better prognosis after repeat pulmonary metastasectomy" 27 and "repeat metastasectomy for recurrent pulmonary metastasis also provided a favorable overall survival $(\mathrm{p}<0.041) .{ }^{20}$ To undergo a second metastasectomy a patient has to have survived, and been without evidence of disease for a reasonable length of time, to meet the criteria for each subsequent operation. The problem is exemplified by Sardenberg and colleagues. Survival was measured from the first thoracotomy for pulmonary metastasectomy (confirmed with the first author) and was 15,45 and 48 months, in 35 patients having only one surgical episode, 24 who had 3 and 13 who had three. The authors provide a statistical analysis $(p=0.077)$ of the association between more thoracotomies and longer survival. They neglect the fact in their interpretation that survival after surgery, and for a reasonable period of time, was a requirement to move to the next analytical group. ${ }^{19}$ This way of presenting the data maximises survivor bias: ongoing survival is an entry criterion to having a further metastasectomy operation.

We found no data, or even a narrative account, concerning the effect of surgery on symptoms. The patients who are regarded as candidates for metastasectomy are generally detected on surveillance and presentation with symptoms probably distinguishes patients as being not suitable for metastasectomy, either because it represents extrapulmonary disease or the pulmonary disease is too advanced. The evidence cited in NICE guidance ${ }^{3}$ is as follows: "Detection on the basis of symptoms occurred in 21 patients. Fifteen of these patients presented between scheduled visits. Seven patients were symptomatic primarily on the basis of their metastatic pulmonary disease. These patients had diffuse metastatic disease in all cases, with documented synchronous recurrence outside the lung, and none was resectable." ${ }^{5}$ What is implicit in many of the reports reviewed is that ultimately they call a halt to repeated thoractomies because the patient respiratory function will not withstand further surgery and loss of lung tissue.

Two publications ${ }^{45}{ }^{46}$ which appeared in 2011 after completion of our review and data analysis, and following submission, have been brought to our attention by reviewers. They come from prominent North American institutions and appeared in a specialist thoracic surgical journal, The Annals of Thoracic Surgery. The report from Brigham and Women's Hospital, Boston, Massachusetts states in its title "Repeated and aggressive pulmonary resections for leiomyoma metastases extends survival." The report is of 82 patients with a variety of bone and soft tissues sarcomas between 1989 and 2004. Repeat metastasectomy was performed in 28/82 with some patients having three, four or five thoracic operations. Operated patients with leiomyosarcoma $(31 / 82)$ had a median survival of 70 months compared with 24 months for other sarcoma subtypes. No control data for survival among comparable patients, not operated upon, are 
provided. The text confirms that the surgery was repeated and aggressive but that survival was extended as a result cannot be inferred from the data presented for the reasons given already.

The other report, from the Massachusetts General Hospital, is of 97 patients with 13 sarcoma subtypes operated on for pulmonary metastases between 2002 and $2008 .^{46}$ They report that of $69 \%$ of 29 patients who had multiple operations were alive at 5 years compared with $41 \%$ of 60 patients who had a single operation and find the difference to be statistically significant and the bottom line of the conclusions reads "Repeated pulmonary metastasectomy in select patients may improve survival despite recurrent disease." But patients have first to be survivors to be candidates for surgery, a point the authors themselves make in their discussion "Patients in whom disease rapidly recurred after surgery (either as a local recurrence or disseminated disease) were probably selected out from repeated surgical resection." 46 Patients who thus meet the criteria for a second operation must necessarily live longer making the argument circular and the statistical test spurious.

Neither of these papers provides evidence on symptomatic benefit for these patients.

While there are some long-term survivors among those who have this surgery, the absence of control data leaves Aberg's challenge ${ }^{38} 39$ unrefuted. His hypothesis was that patients destined to survive longer are more likely to be selected for surgery and it is the process of selection, rather than the effect of pulmonary metastasectomy, which is responsible for any survival difference perceived. Although it would of course be challenging to perform, a randomised controlled trial is now necessary if we are to see the signal from the noise in this area of clinical practice.

Acknowledgements We are grateful to Peter Goldstraw, lan Judson, Fergus Macbeth, Meirion Thomas and Penella Woll for reading and commenting helpfully on earlier versions of this manuscript. At Thames Cancer Register we thank Marie Horton and Alexander Massey for data analysis.

Contributors TT instigated the study, reviewed and revised data extraction, created the data tables, did a critical textual review, wrote the first draft and edited all subsequent drafts. FF did the initial data extraction and created the final versions of the figures. MS did the initial literature search and subsequent updated literature searches. HM was responsible for identification, extraction and analysis of comparative data from the Thames Cancer Registry. MU oversaw data analysis, interpretation and presentation. All authors reviewed the manuscript at each stage and have approved the submitted version.

Competing interests None.

Provenance and peer review Not commissioned; externally peer reviewed Data sharing statement We are willing to share data.

\section{REFERENCES}

1. Kager L, Zoubek A, Potschger U, et al. Primary metastatic osteosarcoma: presentation and outcome of patients treated on neoadjuvant Cooperative Osteosarcoma Study Group protocols. $J$ Clin Oncol 2003;21:2011-18.

2. Gelderblom H, Jinks RC, Sydes $M$, et al. Survival after recurrent osteosarcoma: data from 3 European Osteosarcoma Intergroup (EOI) randomized controlled trials. Eur J Cancer 2011;47:895-902.
3. National Institute for Health and Clinical Excellence (NICE). Guidance on cancer services. Improving outcomes for people with sarcoma. The manual. The National Institute for Health and Clinical Excellence (NICE). 2006. http://www.nice.org.uk/nicemedia/live/ 10903/28934/28934.pdf (accessed 21 Sep 2012).

4. National Institute of Health and Clinical Excellence (NICE). Guidance on cancer services. Improving outcomes for people with sarcoma. The evidence review. Institute of Health and Clinical Excellence, 2006. http://www.nice.org.uk/nicemedia/live/10903/ 28936/28936.pdf (accessed 21 Sep 2012).

5. Whooley BP, Gibbs JF, Mooney MM, et al. Primary extremity sarcoma: what is the appropriate follow-up? Ann Surg Oncol 2000;7:9-14.

6. Internullo E, Cassivi SD, Van Raemdonck D, et al. Pulmonary metastasectomy: a survey of current practice amongst members of the European Society of Thoracic Surgeons. J Thorac Oncol 2008;3:1257-66.

7. Van Raemdonck D, Friedel G. The European Society of Thoracic Surgeons Lung Metastasectomy Project. J Thorac Oncol 2010;5: S127-9.

8. Liberati A, Altman DG, Tetzlaff J, et al. The PRISMA statement for reporting systematic reviews and meta-analyses of studies that evaluate healthcare interventions: explanation and elaboration. $B M J$ 2009;339:b2700.

9. Moher D, Liberati A, Tetzlaff J, et al. DG. Preferred reporting items for systematic reviews and meta-analyses: the PRISMA statement. BMJ 2009;339:b2535.

10. Antunes M, Bernardo J, Salete M, et al. Excision of pulmonary metastases of osteogenic sarcoma of the limbs. Eur J Cardiothorac Surg 1999;15:592-6.

11. Harting MT, Blakely ML, Jaffe N, et al. Long-term survival after aggressive resection of pulmonary metastases among children and adolescents with osteosarcoma. J Pediatr Surg 2006;41:194-9.

12. Briccoli A, Rocca M, Salone M, et al. High grade osteosarcoma of the extremities metastatic to the lung: long-term results in 323 patients treated combining surgery and chemotherapy, 1985-2005. Surg Oncol 2010;19:193-9.

13. Chen F, Miyahara R, Bando T, et al. Prognostic factors of pulmonary metastasectomy for osteosarcomas of the extremities. Eur $\mathrm{J}$ Cardiothorac Surg 2008;34:1235-9.

14. Buddingh EP, Anninga JK, Versteegh MI, et al. Prognostic factors in pulmonary metastasized high-grade osteosarcoma. Pediatr Blood Cancer 2010;54:216-21.

15. Gadd MA, Casper ES, Woodruff JM, et al. Development and treatment of pulmonary metastases in adult patients with extremity soft tissue sarcoma. Ann Surg 1993;218:705-12.

16. Smith R, Pak Y, Kraybill W, et al. Factors associated with actual long-term survival following soft tissue sarcoma pulmonary metastasectomy. Eur J Surg Oncol 2009;35:356-61.

17. Rehders A, Hosch SB, Scheunemann P, et al. Benefit of surgica treatment of lung metastasis in soft tissue sarcoma. Arch Surg 2007;142:70-5.

18. Garcia Franco CE, Algarra SM, Ezcurra AT, et al. Long-term results after resection for soft tissue sarcoma pulmonary metastases. Interact Cardiovasc Thorac Surg 2009;9:223-6.

19. Sardenberg RA, Figueiredo LP, Haddad FJ, et al. Pulmonary metastasectomy from soft tissue sarcomas. Clinics (Sao Paulo) 2010;65:871-6.

20. Chen F, Fujinaga $\mathrm{T}$, Sato $\mathrm{K}$, et al. Significance of tumor recurrence before pulmonary metastasis in pulmonary metastasectomy for soft tissue sarcoma. Eur J Surg Oncol 2009;35:660-5.

21. Garcia Franco CE, Torre W, Tamura A, et al. Long-term results after resection for bone sarcoma pulmonary metastases. Eur $J$ Cardiothorac Surg 2010;37:1205-8.

22. Snyder C, Saltzman D, Ferrell K, et al. A new approach to the resection of pulmonary osteosarcoma metastases. Results of aggressive metastasectomy. Clin Orthop Relat Res 1991;270:246-53.

23. Blackmon SH, Shah N, Roth JA, et al. Resection of pulmonary and extrapulmonary sarcomatous metastases is associated with long-term survival. Ann Thorac Surg 2009;88:877-84.

24. Gossot D, Radu C, Girard P, et al. Resection of pulmonary metastases from sarcoma: can some patients benefit from a less invasive approach? Ann Thorac Surg 2009;87:238-43.

25. Casson AG, Putnam JB, Natarajan G, et al. Efficacy of pulmonary metastasectomy for recurrent soft tissue sarcoma. J Surg Oncol 1991;47:1-4.

26. Briccoli A, Rocca M, Salone M, et al. Resection of recurrent pulmonary metastases in patients with osteosarcoma. Cancer 2005;104:1721-5 
27. Chen F, Miyahara R, Bando $\mathrm{T}$, et al. Repeat resection of pulmonary metastasis is beneficial for patients with osteosarcoma of the extremities. Interact Cardiovasc Thorac Surg 2009;9:649-53.

28. Thomford NR, Woolner L, Clagett $O$. The surgical treatment of metastatic tumours in the lung. $J$ Thorac Cardiovasc Surg 1965:49:357-63.

29. Garcia-Yuste M, Cassivi S, Paleru C. Thoracic lymphatic involvement in patients having pulmonary metastasectomy: incidence and the effect on prognosis. J Thorac Oncol 2010;5: S166-9.

30. Casson AG, Putnam JB, Natarajan G, et al. Five-year survival after pulmonary metastasectomy for adult soft tissue sarcoma. Cancer 1992;69:662-8.

31. Glasziou $\mathrm{P}$, Chalmers I, Rawlins $\mathrm{M}$, et al. When are randomised trials unnecessary? Picking signal from noise. BMJ 2007;334:349-51.

32. Martini N, Huvos AG, Mike V, et al. Multiple pulmonary resections in the treatment of osteogenic sarcoma. Ann Thorac Surg 1971;12:271-80.

33. Beattie EJ, Harvey JC, Marcove R, et al. Results of multiple pulmonary resections for metastatic osteogenic sarcoma after two decades. J Surg Oncol 1991;46:154-5.

34. van Geel AN, Pastorino U, Jauch KW, et al. Surgical treatment of lung metastases: the European Organization for Research and Treatment of Cancer-Soft Tissue and Bone Sarcoma Group study of 255 patients. Cancer 1996;77:675-82.

35. van Geel AN, Rm van Der SJ, Schmitz PI. Which soft tissue sarcoma patients with lung metastases should not undergo pulmonary resection? Sarcoma 2002;6:57-60.
36. Billingsley KG, Burt ME, Jara $\mathrm{E}$, et al. Pulmonary metastases from soft tissue sarcoma: analysis of patterns of diseases and postmetastasis survival. Ann Surg 1999;229:602-10.

37. Utley M, Treasure T. Interpreting data from surgical follow-up studies: the role of modeling. J Thorac Oncol 2010;5:S200-2.

38. Aberg T, Malmberg KA, Nilsson B, et al. The effect of metastasectomy: fact or fiction? Ann Thorac Surg 1980;30:378-84

39. Aberg T. Selection mechanisms as major determinants of survival after pulmonary metastasectomy. Ann Thorac Surg 1997;63:611-12.

40. Greenberg SA. How citation distortions create unfounded authority: analysis of a citation network. BMJ 2009;339:b2680.

41. Fiorentino F, Vasilakis C, Treasure $\mathrm{T}$. Clinical reports of pulmonary metastasectomy for colorectal cancer: a citation network analysis. Br J Cancer 2011;104:1085-97.

42. Utley M, Treasure $\mathrm{T}$. The use of scoring systems in selecting patients for lung resection: work-up bias comes full-circle. Thorac Surg Clin 2008;18:107-12.

43. Nakas A, Klimatsidas MN, Entwisle J, et al. Video-assisted versus open pulmonary metastasectomy: the surgeon's finger or the radiologist's eye? Eur J Cardiothorac Surg 2009;36:469-74.

44. Detterbeck FC, Grodzki T, Gleeson F, et al. Imaging requirements in the practice of pulmonary metastasectomy. $J$ Thorac Oncol 2010:5:S134-9.

45. Burt BM, Ocejo S, Mery CM, et al. Repeated and aggressive pulmonary resections for leiomyosarcoma metastases extends survival. Ann Thorac Surg 2011;92:1202-7.

46. Kim S, Ott HC, Wright CD, et al. Pulmonary resection of metastatic sarcoma: prognostic factors associated with improved outcomes. Ann Thorac Surg 2011;92:1780-6. 